\title{
The Use of Compliance as a Way to Drive Credibility for Cloud Hosting
}

\author{
Adriana Maria Miguel Peixe ${ }^{1}$, Jorge Balsan ${ }^{2}$, Marcio Rodrigo Santos ${ }^{3}$, José Simão de Paula Pinto \\ ${ }^{1,3}$ UFPr, Information Management Doctorate Program, Av. Prefeito Lotário Meissner, 632 - Campus III, Jardim Botânico \\ CEP: 80210-170 - Curitiba / PR - (Brazil) \\ ${ }^{2}$ UFSC - Masters in Production Engineering, Av. Prefeito Lotário Meissner, 632 - Campus III, Jardim Botânico \\ CEP: 80210-170 - Curitiba / PR - (Brazil) \\ ${ }^{4}$ Dr. in medicine, focusing on information technology applied to teaching and research in surgery \\ Av. Prefeito Lotário Meissner, 632 - Campus III, Jardim Botânico, CEP: 80210-170 - Curitiba / PR - (Brazil)
}

\begin{abstract}
Compliance can be understood as credibility, a competitive advantage for providers of cloud hosting services. Deployment as a way of promoting credibility for cloud hosting has grown in relevance due to the need for capacity, availability, integrity, and security, which are fundamental requirements in this context, as are adequate structure and documentation. Establishing well-defined rules and metrics in dealing with information, as well as its proprietary rights and privacy, grows in relevance at the same rate as the number of users enjoying cloud computing services and the number of attempts to access restricted information through wide range of cyberattacks. Compliance establishes a comprehensive baseline for an organization's security positioning, thereby reducing the risk of fines, penalties, unplanned downtimes, lawsuits, or business suspension. This study intends to address the cloud data hosting scenario, taking into account this framework and information management for that data, which crosses geo-political boundaries. The article's methodological outline is characterized as a bibliographic and exploratory research. In the descriptive analysis, it was found that it may be seen as a competitive advantage for hosting in the cloud, driving the need for investments in security for the purpose of preventing unauthorized access. The study infers that cloud computing is a safe and low-cost option for storing information and systems.
\end{abstract}

Keywords: Information management, Compliance, Data, Cloud hosting

\section{Introduction}

Recent decades have seen a significant growth in the search for information, as well as for tools that facilitate access and maintenance. In the mid-1960s, data was processed with a greater emphasis on accounting applications and with a focus on solving mathematical problems, merely to assist and streamline calculation processes. From the 1980 s to date, the focus has become greater on competitive systems running at the client's facilities, where information plays a dominant role [15]. The chain represented by the triad: data, information and knowledge has displayed its importance, in an ongoing process of evolution of the technologies deployed, emphasizing processes such as digitalizing, data and hosting environment trustworthiness, availability, security, among others.

With the evolution of hardware and software technologies used on the Internet, strategies such as $\mathrm{SaS}$ - Software as Service, Iaas - Infrastructure as a Service and PaaS Platform as a Service, applications and even complete environments are hosted in the cloud. This leads to a number of usage advantages, such as downsizing and even complete elimination of data centers installed in the company or industry facilities. However, this use brings with it additional concerns over corporate data being stored outside company limits, often in unknown locations.

Given the above, the guiding question of this work comes up: How to deal with the scenario of cloud data hosting, taking into account the need for data compliance and information management within this environment to achieve safe and reliable ways to use it?
This study's objective is to approach information management in this environment that extends beyond geographical boundaries.

In this highly competitive and technological environment, the study by [13], highlights several companies offering cloud data storage services, such as Dropbox, Google Drive, Microsoft one drive, Amazon Drive, etc. should be mentioned, as well as mentioning constraints, of cost or space, limiting the access to these for those who cannot afford the storage-related costs. In their study [13] proposed alternatives so that users, developers, or even entities would be able to store larger volumes of data distributed at low cost, and with higher security [13]. The aforementioned authors, when carrying out the study, created proposals for access and storage to allow for larger volumes of data, securely and at a reduced cost, thereby avoiding or minimizing expenses incurred with the purchase or rental of devices or storage resources such as HDs, pen drives or storage clouds with contracted plans. This data could be in the form of digital information, satellite images, visual information, text or unstructured data [31]. According to [16], information security is a collection of activities that protects information systems and the data stored in them. There are different aspects that characterize security in information systems, called security services. The basic security services are authenticity, confidentiality, availability, integrity and non-retractability [16]. The origin of the right to data protection dates back to the end of the 19th century, when new technologies began to appear capable of exposing people's intimate lives, that is, it is linked to the emergence of the right to privacy. The right's milestone is the famous article by Samuel Warren and Louis 


\section{International Journal of Science and Research (IJSR) \\ ISSN: 2319-7064}

ResearchGate Impact Factor (2018): 0.28 | SJIF (2019): 7.583

Brandeis "The right to privacy", in which the authors defended the right of individuals to be left alone (the right to be let alone) given the appearance of new inventions and business methods [30]. According to [4], the importance of this research is due to the growing number of users making use of cloud computing services. Thus, the amount of information is increasing, as is increasing the interest of people with malicious intent, who endeavor to take advantage by harming others [4].

This article is structured as follows: Introduction: with an approach to Data Compliance; Development: covering topics such as: Data, Information and Knowledge; Cloud Computing and Cloud Hosting; Compliance in Cloud-based Data Hosting Environments; Evolution of Forms of Storage; Corporate Data Centers - hosting within the company; IaaS, PaaS and SaaS; E-government; Government Laws; Brazilian data protection laws. Search results; Conclusion and References.

\section{Development}

\subsection{Data, Information and Knowledge}

Data can be characterized as the basic concept for a chain of concepts that goes by way of information and culminates in knowledge. Author [33] in his findings mentions that modern collaborative innovation approaches require extensive sharing of confidential business information. The protection of business secrets can facilitate sharing among partners, enabling recovery when a third party misappropriates valuable information [33].

[9] argue that the role of technology in promoting the effective use of information is peripheral in relation to behavioral issues. Reuse is explained by [22] as the use of information already existing in the organization to perform the work and make decisions, avoiding unnecessary information collecting, organizing and processing work.

In Table 1, [8] explains the differences among data, information and knowledge.

Table 1: Differences among data, information, and knowledge

\begin{tabular}{|c|c|c|}
\hline Data & Information & Knowledge \\
\hline $\begin{array}{l}\text { Simple observation of } \\
\text { the state of the world }\end{array}$ & $\begin{array}{c}\text { Data with relevance } \\
\text { and purpose }\end{array}$ & $\begin{array}{l}\text { Valuable information } \\
\text { from the human mind }\end{array}$ \\
\hline $\begin{array}{c}\text { Easily structured } \\
\text { Easily obtained by } \\
\text { machines } \\
\text { Often quantified } \\
\text { Easily transferable }\end{array}$ & $\begin{array}{c}\text { Requires unit of } \\
\text { analysis } \\
\text { Requires consensus } \\
\text { on meaning } \\
\text { Necessarily requires } \\
\text { human mediation }\end{array}$ & $\begin{array}{l}\text { Includes reflection, } \\
\text { synthesis and context } \\
\text { Difficult to structure } \\
\text { Difficult to capture } \\
\text { on machines } \\
\text { Often tacit } \\
\text { Difficult to transfer }\end{array}$ \\
\hline
\end{tabular}

Source: [8].

Information, in its turn, can be characterized as being the data processed in order to generate an idea about something.

Once information is produced, creating situations in which other companies have incentive to produce the same information again is socially wasteful, unless production is less costly than transmission [17].
[33] mentions in his findings that structured updated properly applied and secured KNOWLEDGE is a major competitive advantage. Authors [6], show in their study that the knowledge is an asset, a production factor, and can be explained, modeled, and inserted in knowledge systems. In contemporary society, information and knowledge have become even more essential for organizational competitiveness and growth, amid complex and continually changing market contexts.

\subsection{Cloud Computing and Cloud Hosting}

Cloud computing is one such powerful technology to perform massive scales of data and complex computing [26]. Cloud computing is becoming more common in day-to-day computing due to its ability to share globally distributed resources.

It is a new computing paradigm - an online service whereby hardware and software services are delivered to customers, depending on their requirements, and are paid for as an operating expense without incurring high costs [3].

Cloud computing may be a set of policies and procedures that, typically, are supported by a physical or technical infrastructure that enables corporations to recover quickly from disasters and ensure business continuity, should a system crash or any kind of natural or human-made disaster take place. A chance of knowledge loss which may also cause the loss, [29].

According to authors [26]),[3],[29]in their studies, cloud computing can then be defined as a set of policies and procedures normally supported by a physical or technical infrastructure that allows companies to recover quickly from disasters and guarantee business continuity should a system crash or any kind of natural or human-made disaster take place, [29].

Cloud is a current reference to the large worldwide network of computers, created in 1969 in the United States, for the purpose of linking research centers. With time, the internet went on to add services such as e-commerce, banking, online services, etc. With its Difu, the World Wide Web has gained momentum, developing the current format, with many possibilities for the future.

With the same rate of growth as the Internet, virtual threats grew, in an unbridled quest for illegal information and financial gains. Industries and businesses are not excluded from these attacks. A number of factors may have led to an increase in the theft of business secrets, such as the globalization of supply chains, rapid advances in ICTs, the growing use of digital storage and external data processing facilities - including in the cloud, the growing importance of know-how as a source of competitive advantage and greater professional mobility [33].

Cloud Computing offers computing services over the internet, allowing access to files and the execution of different tasks over the internet, without the requirement to install software programs or applications on the computer or device. The systems are stored on shared servers and 


\section{International Journal of Science and Research (IJSR) \\ ISSN: 2319-7064}

ResearchGate Impact Factor (2018): 0.28 | SJIF (2019): 7.583

interconnected over the internet, allowing them to be accessed anywhere in the world [14]. In order to be able to offer different services on a single robust server, connected to the internet, resources are split in the server, giving rise to several virtual machines. The guarantee of elasticity and payment on demand are the main reasons that attract people to join this technology. A computer system model can be called cloud computing and allow network access, on demand, to a pool of shared computing resources (for example: networks, servers, storage, applications and services), which can be quickly provisioned and released with minimal effort from management or service provider interaction [25]. Figure 1 exemplifies cloud computing.

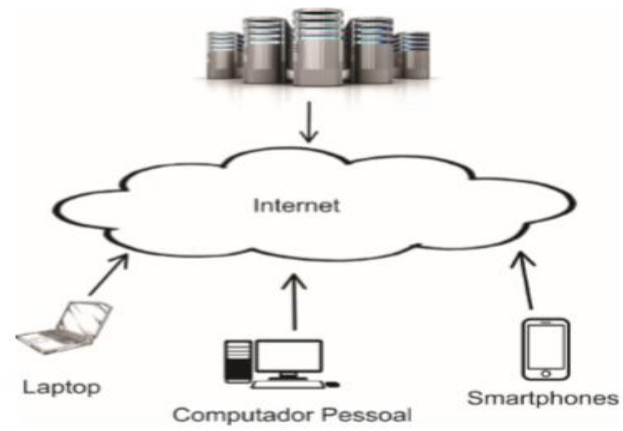

Figure 1: Cloud Computing

Source: [11].

Cloud environments must have the following essential characteristics, as shown in table 2, [25]:

Table 2: Cloud Environments and their Essential Features

\begin{tabular}{|c|c|c|c|c|}
\hline (I) & (II) & (III) & (IV) & (V) \\
\hline $\begin{array}{c}\text { On-demand } \\
\text { service }\end{array}$ & $\begin{array}{c}\text { Wide access to } \\
\text { network service }\end{array}$ & $\begin{array}{c}\text { Resource } \\
\text { pool }\end{array}$ & $\begin{array}{c}\text { Fast } \\
\text { elasticity }\end{array}$ & $\begin{array}{c}\text { Measurable } \\
\text { services }\end{array}$ \\
\hline
\end{tabular}

Source: Drafted by the authors adapted from [25].

In traditional computing, according to the authors [14], the resources available for a given service are fixed, for instance, the number of servers and the space for storage. On the other hand, in the cloud model, resources are capable of adapting to variations in the demand flow, optimizing costs and responding in a dynamic and fast manner to such variations. There is, therefore, an economy in the project and a capacity to react faster to changes in demands [14].

\subsection{Compliance in Cloud Data Hosting Environments}

In its commercial meaning, compliance refers to meeting legal obligations. This reduces the risk of fines, penalties, unplanned downtimes, lawsuits or suspension of the business.

As companies grow, they will need to meet requirements, that is, legal obligations such as a business license to operate in a given city and collect taxes owed from the activity. One of the cloud data compliance concerns is the need for investment in security with a view to rendering unauthorized access impossible [12],[38].

Regardless of hardware and software technology and any security features applied, individuals with malicious intent, aiming to obtain some form of self-benefit, create a wide variety of ways to violate the security mechanisms used [4]
The concept of "IT Security" is limited to employing certain measures to have the best possible protection for an organization's assets.

Similar to IT security, in the end, this leads companies to practicing due diligence in protecting digital assets. However, the reason is different: centered on third-party requirements, such as governments, IT security framework, or customer contractual terms [46]. Table 1 explains the difference between IT Security and Compliance.

Table 1: Difference between Security and Compliance

\begin{tabular}{|c|c|}
\hline IT security & Compliance \\
\hline $\begin{array}{l}\text { Practiced for itself, not to satisfy } \\
\text { the needs of others; } \\
\text { Driven by the need to protect } \\
\text { organizational assets from } \\
\text { constant threats; } \\
\text { Never truly concluded, having to } \\
\text { be continuously maintained and } \\
\text { improved. }\end{array}$ & $\begin{array}{l}\text { Practiced to satisfy external } \\
\text { requirements and facilitate } \\
\text { business operations; } \\
\text { Driven by business, not } \\
\text { technical needs; } \\
\text { Completed when the third } \\
\text { party is satisfied. }\end{array}$ \\
\hline
\end{tabular}

Source: Drafted by the authors 2020 adapted from https://www.infonova.com.br/seguranca/tudo-compliancede-ti-importancia-empresas/accessed on 06/04/20.

As confirmed by [46], this framework helps organizations to have standardized security programs, as opposed to one in which controls can be chosen at the administrator's option. This makes it evident that both go together and complement each other, establishing a comprehensive baseline for an organization's security posture. Diligent safety practices are built on this baseline to ensure that the company is covered from all angles [46].

\subsection{Evolution of forms of storage}

Since the earliest days, human beings have looked for ways to store information, as seen in writings and rustic images painted on cave walls, or texts written on stone slabs, wood boards or papyrus. Over the years, information has become a fundamental basis for the evolution of our society. Over time, new techniques have been developed, but with the same goal: preserving information.

Before the digital age, attempts were made to find ways to store data, information, memories and with the advancement of technology, data storage devices with different sizes and storage capacities were emerging.

[36] in their work already show that with the ongoing social, intellectual and technological evolution, mainly after the onset of the industrial era, information storage and transmission methods continually underwent changes, in order to make them more efficient and faster.

Today, in general terms, the evolution of digital storage can be traced from the Jacquard Loom and Charles Babbage's Analytical Machine - which made use of punch cards, to the recent storage in the cloud, along which many technologies were created and evolved. Table 2 gives a simplified overview of the evolution of data storage. 


\section{International Journal of Science and Research (IJSR) \\ ISSN: 2319-7064}

ResearchGate Impact Factor (2018): 0.28 | SJIF (2019): 7.583

Table 2: Evolution of data storage

\begin{tabular}{|c|c|c|}
\hline Year 1725 & Punch Card & ND \\
\hline Year 1890 & $\begin{array}{c}\text { Paper tape } \\
\text { in telex) }\end{array}$ & $\begin{array}{c}5 \text { to 8 columns, up to 120k on } \\
340 \text {-yard tapes with 10 bytes } \\
\text { inch. perforated card - 60 to } \\
120 \text { bytes in up to 90 } \\
\text { columns (usually 80) }\end{array}$ \\
\hline Year 1947 & Williams Tube & $0.0625 \mathrm{~KB}$ \\
\hline Year 1950 & Memory drum & $10 \mathrm{~KB}$ \\
\hline Year 1951 & UNISERVO & 128 bits per inch \\
\hline Year 1956 & IBM 350 RAMAC & $4.4 \mathrm{MB}$ \\
\hline Year 1972 & Cassette & $660 \mathrm{~KB}$ per side \\
\hline Year 1976 & 5.25 floppy disk & $1.2 \mathrm{MB}$ \\
\hline Year 1980 & IBM 3380, ST-506 & $2.52 \mathrm{~GB}, 5 \mathrm{MB}$ \\
\hline Year 1987 & DAT & $1.3 \mathrm{~GB}$ \\
\hline Year 1990 & CD-R & $700 \mathrm{MB}$ \\
\hline Year 1993 & MiniDisc MD Data & $140 \mathrm{MB}$ \\
\hline Year 1994 & ZIP & $100 \mathrm{MB}$ \\
\hline Year 1996 & Seagate Barracuda & $2.5 \mathrm{~GB}$ \\
\hline Year 1999 & IBM 170 Microdrive & $170 \mathrm{MB}$ \\
\hline Year 2000 & IBM DiskOnKey, & $8 \mathrm{MB}, 32 \mathrm{MB}$ \\
\hline Year 2008 & Solid-state Drive & $64 \mathrm{~GB}$ \\
\hline 2020 & Cloud storage & Unlimited \\
\hline
\end{tabular}

Source: Drafted by the authors adapted from https://pplware.sapo.pt/internet/a-historia-doarmazenamento-digital/acesso 10_01_2020 website.

Cloud computing is a growing marketing trend, not limited to just companies, regular users are also increasingly submitting their files to the cloud. An astonishing amount of data is generated and stored in remote repositories, making security one of the most addressed points in cloud computing (BOTACIM et al., 2016).

\subsection{Corporate Data Center - in-company hosting}

Data Centers or Data Processing Centers are considered the nervous system of companies. This is where data processing is performed. This space is designed to harbor servers and other equipment, such as switches, routers, access-points, among others. This environment is designed as location of the organization's data storage and processing equipment. Designed with a high level of security, the DCs houses servers and databases, supporting a large volume of information [5].

Data Centers are where storage machine are located and computational systems operate, making it possible to store processing data and outcomes, as well as other services [23].

For [5], [26] all information about a company is stored on a device called a server. This server must be in a cool and safe environment, that is, a space prepared to protect the company from theft and cyber attacks. Maintaining this environment within the company facilities when safer and cheaper solutions already exist, is an unnecessary risk and cost. An example of a safer and cheaper option is cloud computing.

With so many technological advances presentevery day in our environment, tracking and keeping up with this ongoing evolution is critical for ICT professionals. More and more users are using cloud computing, due to its mobility, portability and ease [4]. In cloud computing, IaaS providers are comprised of virtualized machines, containers and switches, interconnected by a virtual private network [21].

\section{6 IaaS, PaaS and SaaS}

Internet access has been enhanced in both, quality and quantity, enabling more and more users around the world to access the services provided by the web. The term cloud computing was introduced in 2006 when Google's CEO (Chief Executive Officer) at the time, Eric Schmidt, used the term to describe the company's own services, and again shortly after, when Amazon used the same term to launch its service calling it the Amazon Elastic Compute Cloud (Amazon EC2). Using Amazon EC2 eliminates the initial need to invest in hardware. Figure 2 shows the definition of cloud computing, according to author [40],[3].

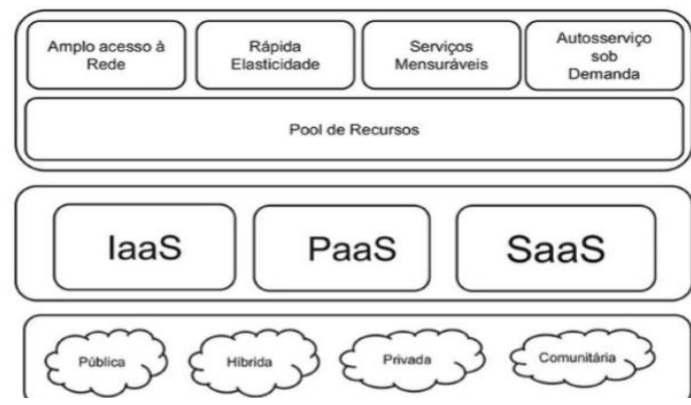

Figure 2: Definition of cloud computing according to NIST [40]

Source: NIST [40]

Like any other computing system, cloud computing environments are susceptible to errors, which can lead to service failures. Optical fibers, one of the modern communication means, has been used widely as the physical medium for information traffic, with its useincreasing in number of access points, according to the Brazilian Internet Association, in "January-April 2019 there were 907.5 thousand new fiber access points" in Brazil.

New cabled internet connections ended the first quarter of 2019 with an increase of $1.21 \%$, which meant a net addition of 378.4 thousand new access points. At the end of April, this market totaled 31.6 million active connections, according to data released by ANATEL, this Friday, 05/31 [44].

This ease of access and the high quality of information, which is constantly evolving, has made new forms of services available, such as SaaS - Software as a Service in which a software is made available on the Internet and users register and use the system through the internet.

IaaS - Infrastructure as a Service, provides remote servers with operating systems, database software and other ancillary applications on the Internet, i.e., companies can move their entire data centers to the cloud, saving on the purchase of physical equipment,[3],[35].

PaaS - Platform as a Service, consists in the hosting service itself as well as the implementation of hardware and software, which is used to deliver applications through the

\section{Volume 9 Issue 7, July 2020 www.ijsr.net}




\section{International Journal of Science and Research (IJSR) \\ ISSN: 2319-7064}

ResearchGate Impact Factor (2018): 0.28 | SJIF (2019): 7.583

Internet. Users build their own applications on a cloud platform, in this modality, [3],[24].

SaaS - Software as a Service, is a modality of cloud computing that according to studies performed in 2019 by Araujo establishes that $\mathrm{SaaS}$ is a service delivery system through software used by the internet. Sites like Facebook and Twitter or apps like Skype, OneDrive, Google Docs and Office 365 work in this manner. There is the example of Skype where everything is made available in the cloud, so that many users can access the service through browsers or software [3],[2].

\subsection{E-government}

When the government is capable of using and applying analytics on its big data, there is significant progress as regards the management of public services, agencies, in dealing with traffic congestion or preventing crime. However, despite using big data having many advantages, governments must also deal with issues of transparency and data privacy [37].

\subsection{Government Laws}

For [33] trade secret regimes are ineffective due to low levels of legal protection, legal fragmentation between and within countries and regions, as well as inadequate enforcement. The resulting legal insecurity is particularly problematic in light of the current business environment, which is characterized by globally dispersed RD\&I, labor mobility and dependence on Information and Communication Technologies (ICTs) [33].

The adequacy of this analogy is reinforced by Senate Bill of Law no. 330/2013 (PLS 330/2013), which intends to establish principles, guarantees, rights and duties withrespect to protection, treatment and use of personal data [32].

\subsubsection{Brazilian data protection legislation}

\section{(a) Data Protection Law}

Based on the assumption that private information must not be made public, [39], states that due to the cyber sector being public, this makes it difficult to obtain legal protection and confidentiality of information. According to [39], "The most precious niches of privacy are at risk. Current accounts, income tax returns, credit card numbers and transactions, passport data, names and addresses of business and personal contacts [...]" [39, p. 107].

In Brazil, confidential data regulation and treatment is performed by control agencies. In the absence of specific regulations in Brazil, the solution was to seek in comparative law, by analogy, some way of enabling data access so that the control agencies can exercise their constitutional and legal powers without compromising the essential core of the confidentiality of taxpayer fiscal data. It is worth bearing in mind that the Law of Introduction to the rules of Brazilian Law (Decree-Law No. 4,657 / 1942) brings this possibility in article 4: "When the law is omissive, judges must rule on the case in point by applying by analogy, the customs and general principles of the Law" [32].

\section{(b) Protection of Personal Data - MPV 869}

The Brazilian Federal Constitution did not expressly conceive a general personality right. However, the constitutional principle of the dignity of the human person postulates the assurance of protection of the personality and of the consectaries assigned to it. In Ingo Sarlet's lesson, the connection between the right to privacy and the dignity of the human person is justified insofar as the preservation of a sphere of private life is essential to the very mental health of human beings, assuring the full development of their personality. [34, p. 443).

First of all, what the data represents for your company must be defined and established which information is valuable for making decisions and then follow through with the process. This will establish the origin, processing and way of storing said data [14].

\section{Methodology}

The methodological procedures that were applied in the research, regarding the classification of the nature of the variables are qualitative, typology / procedures of the documentary research, objective of the descriptive approach.

The sample size for data collection was based on articles. Data analysis was performed by reading and bibliography research. In documentary, descriptive and explanatory research, when aligned with investigation, research is carried out by social researchers who are concerned with practical action, providing a new take of the problem [41]. To this end, in seeking to provide an overview of the problem, of the approximate type through the researcher's understanding of the phenomenon or case study that results in enhanced ideas [10]. The enhancement of these ideas can be done through good governance which reflects in quality services, results and greater transparency for stakeholders by applying the approach to the cloud data hosting scenario, taking into account the compliance of this data and information management in this environment that extends being geopolitical boundaries. In this context, for the research to take effect, the intent was to address the scenario of cloud data hosting, taking into account the compliance of the data and information management in this environment that extends being geo-political boundaries. Table 3 sets out the methodological procedures applied in this research, in order to achieve the research objective.

Table 3: Methodological Procedures

\begin{tabular}{|l|l|}
\hline \multicolumn{2}{|c|}{ Methodology } \\
\hline Search classification criteria & Classification \\
\hline Nature of variables & Qualitative \\
\hline Procedures & Document-based \\
\hline Timeframe & 2018 to 2019 \\
\hline Objective & Descriptive \\
\hline Data source & Articles \\
\hline Data Analysis & Reading \\
\hline
\end{tabular}

Source: Elaborated by the authors (2020).

\section{Research outcomes}

Security and compliance go together, complementing each other and are indispensable. The fierce competitiveness in 


\section{International Journal of Science and Research (IJSR) \\ ISSN: 2319-7064}

ResearchGate Impact Factor (2018): 0.28 | SJIF (2019): 7.583

the labor market, sensitizes us to be in constant movement in search of improvements. Competitive intelligence becomes mandatory, anticipating the movements of companies is essential, using Corporate Responsibility.

In the corporate administrative and legal world, compliance is defined as "the duty to deliver, to be in compliance and to enforce internal and external laws, guidelines and regulations, seeking to reduce risks linked to reputation and the legal / regulatory aspects" [7, p. 2]. In Corporate Responsibility, governance agents must zeal for the economic and financial viability of organizations, reducing negative external factors of their business and operations, while increasing the positive ones, taking into account, in their business model, the various types of capital (financial, manufactured, intellectual, human, social, environmental, reputational, etc.) in the short, medium and long terms.

For this to happen today, the job market must be open to contribute in terms of managing information and the various technological devices and equipment that are used to provide better performance in organizational processes, thus generating more value for business and reducing errors until even reaching the implementation of cloud-based computing environments.

Cloud computing environments are also susceptible to errors, which may result in service failures. In recent years, the demand for implementation of this framework has increased greatly, given the ethical culture being introduced in the market through laws such as Law $12.846 / 2013$. This Law establishes that companies, foundations, and associations have become civil and administratively accountable.

The international, as well as the national, market may be perceived to continually strive to curb practices harmful to free market and free competition. Nonetheless, not everything is perfect - many of the companies involved in the corruption scandals that occurred in recent years in Brazil already had compliance programs, codes of ethics and principles of corporate governance, i.e., despite being present, these programs were not fully effective, only covering certain employees [27].

This interdependence of security and compliance in organizations can be submitted to an organizational culture alignment process, which can be accomplished through good strategies, resulting in the reduction of non-compliances. This can be achieved by enforcing all internal and external requirements, thereby reducing risks and conflicts and driving continuous business improvement by addressing both, challenges and opportunities.

For [27], this is nothing more than an attempt to effectively comply with rules and laws related to issues of ethical business conduct. In his work, [1], shows actions to support the structuring and deployment:

1) Issue internal norms and regulations.

2) Keep up to date on legislation applicable to the company's activities in connection with of Compliance related activities.
3) Perform Compliance testing on operations, procedures and registries.

4) Draft a crisis management manual and establish/appoint a crisis management team

5) Prepare a Compliance certification test applicable annually.

6) Encourage competition, ethics, overcoming differences and teamwork.

7) Monitor and implement internal control mechanisms linked to the Compliance area.

8) Control and review registration and documentation issues in relation to the sections: "Know your customer "(KYC)"; "Know your supplier"(KYS)"; and "Know your Employee"(KYE)".

9) Establish operational and system controls and tests to prevent and detect money laundering - mainly applicable to financial institutions.

10)Propose and provide support for the development of training courses within the company area of operation and according to the needs of company and staff.

11)Develop and implement support mechanisms (reports) for the organization's executives to provide input for decisions in the Compliance committee. [1, p. 50].

[20], mentions the meaning of the word ethics that according to him comes from the Greek "ethos", which means character or principles that guide a culture, community or a group. Ethos can also be used on a personal level, such as the characteristics of an individual's personality that distinguish his/her actions as correct and just or incorrect and/or unfair [20].

The objective of corporate compliance is to protect the organization from illegal or unethical acts [1]. In an increasingly globalized world in which professionalization and corporate governance practices become prerequisites for suitability and compliance with international rules, especially to guarantee the security potential of companies, it emerges as a powerful tool for integrating good corporate practices with impacts across the organization [18].

Thus, the use of this compliance model enables reliable cloud hosting, where systems are stored on shared servers and interconnected by the internet, so that they can be accessed from anywhere in the world [14].

\section{Conclusion and final considerations}

The study aimed to address the scenario of hosting data in the cloud, addressing the compliance of the data and of the information management applied. Currently, security, capacity, availability, integrity are all fundamental, although to this end, there must be must have a good structure, good documentation to give support to all this.

Compliance may be perceived as credibility, a competitive advantage for those who offer cloud hosting services. However, this requires investments in physical and human infrastructure, and in security, to keep the services competitive and secure. Using it is the way to drive credibility to hosting in the cloud, becoming fundamental for the success of the business. 


\section{International Journal of Science and Research (IJSR) \\ ISSN: 2319-7064}

ResearchGate Impact Factor (2018): 0.28 | SJIF (2019): 7.583

Currently, there still are problems such as availability, which inconveniences users due to the poor functioning of IT solutions, capacity issues, not being able to deliver to the number of users, data leakage, among others, leaving something to be desired in the operational delivery side and, many times, in the viability of a business.

There are many enigmas / problems in the cloud, mainly in relation to the access to personal, company, system data in relation to the lack of security and planning. The paper infers that cloud computing is an example of a more secure and cheaper option for storing information and systems. Companies and individuals even pay goodwill to companies that offer and use compliance, which is still an important credential in this sector.

\section{References}

[1] M. Assi, "Compliance Management and Its Challenges" - São Paulo: Saint Paul, 2013.(book style)

[2] M. M. Araujo, de, "Development of a SaaS for real estate". Monograph judged in the context of DAS 5511: End of Course Project and approved in its final form by the Control and Automation Engineering Course / UFSC, 2019.(technical report style)

[3] S. S. Bhatia,A. Rai,H. Kaur, "An Architectural Framework for the implementation of ERP using Cloud Computing in SMEs: A Literature Survey". International Journal of Science and Research (IJSR) ISSN (Online): 2319-7064 Index Copernicus Value (2015): 78.96 | Impact Factor (2015): 6.391.(journal style)

[4] R.S. Botacim, S.S Athayde, FM de Oliveira, B. M. Xavier, M. de Souza. "Cloud Computing: Evolution and Peculiarity of Services and Information Security". Interdisciplinary Journal of Scientific Thought. ISSN: 2446-6778 $\mathrm{N}^{\circ} 1$, volume 2, article $\mathrm{n}^{\circ} 19$, January / June 2016 DOI: http://dx.doi.org/10.20951/24466778/v2n1a19. Access 10_01_2020.(journal style)

[5] D. S. Camargo, C. C. Miers. "Open Source Environmental Monitoring for Data Center". In: SBC ERAD -RJ, 2015, Rio de Janeiro. Conference article [...]. Rio de Janeiro: [sn], 2015. (conference style)

[6] R. B.Caumo, B. D.Fraga, R. C. dos. Pacheco Santos, D.Sell, "The Web as a Source in the Construction of Knowledge Systems", 2018.(book style)

[7] M. A.Coimbra, V.Manzi."The. Compliance Manual”. 1st edition. Atlas Publisher: São Paulo. 2010.(book style)

[8] T. H. Davenport."Information ecology: why technology alone is not enough for success in the information age". São Paulo: Futura, 1998a.(book style)

[9] T. H. Davenport, L. Prusak."Information ecology: why technology alone is not enough for success in the information age". São Paulo: Futura, 1998.(book style)

[10] A. C. Gil."How to Prepare Research Projects" - 6th Ed. São Paulo: Atlas, 2017.(book style)

[11] P.Gupta, S.Gupta."Mobile cloud computing: the future of cloud". International Journal of Advanced Research in Electrical, Electronics and Instrumentation Engineering, v. 1, n. 3, pp. 134- 145, 2012. Cited 3 times on pp. 9, 22 and 26.(journal style)
[12] J. G. T. Haramain. "Awareness on Features of Compliance Documentation among Local Government Officials in Barangay Mother Tamontaka, Cotabato City". International Journal of Science and Research (IJSR) ISSN: 2319-7064 Impact Factor: 7.426, 2018.(journal style)

[13] M. Heredia, M. A Flavio Junior, M. A.V. Vasques, B. A da Silva Pontes. "Technical Development or Fragmented Cloud Storage Using Raspberry Pi for Cost Reduction and Security Gain". Applied Computing Magazine. v. 6, n. 1, ISSN 2316-7394, 2017.(technical report style)

[14] J. S. P. Inoue, M. V do A. R Bittencourt, S. B. Pinto,R. S. Geribello, M. of S. Amarante."Industry 4.0 Impacts of Information Technology on the New Industry". Research and Action V5 N1: June ISSN 2447-0627, 2019. (journal style)

[15] IMBOK, "The information management body of knowledge", 08/23/2004.(book style)

[16] D.KIM, M. G Solomon. "Fundamentals of Information Systems Security”. ISBN 978-85-216-2507-0, 1st ed., Rio de Janeiro: Editora LTC, 2014.(book style)

[17] E. W. Kitch."The law and economics of rights in valuable information". Journal of. Legal Studies, v. 9, pp. 683-724, 1980. (journal style)

[18] F. G. Knoerr, S. P Marchi,L. Baldissera."Business Ethics, Compliance and Labor Third Party: Possibility or Utopia?" DIREITO UFMS Magazine | Campo, MS | v.5 | n.1 | pp. 189 - 207 | Jan. / Jun. 2019. (journal style)

[19] W. M.Landes, R. A. Posner. The economic structure of intellectual property law. Cambridge: Harvard University Press, Kindle Edition (ebook), 2003.(book style)

[20] S. Lackburn. Oxford Dictionary of Philosophy. Rio de Janeiro: Zahar, 1997. (book style)

[21] F.Liu, J.Tong, J. B. Mao, J. R. Messina, L. Badger, D'. N. Leaf."Cloud Computing Reference Architecture: Recommendations of the National Institute of Standards and Technology". (Special Publication 500292). CreateSpace Independent Publishing Platform, USA, 2012.(technical report style)

[22] Da Marchand, WJ. Kettinger, JD. Rollins. "Information orientation: The link to business performance". Oxford: Oxford University Press, 2001.(book style)

[23] F. Mehdipour, H. Noori,B. Javadi.Energy-Efficient "Big Data Analytics in Datacenters". Advances In Computers, [sl], pp. 59-101, Apr 2016. Available at: <http://twixar.me/3fX1>. Accessed: 10 Jan. 2020.(journal style)

[24] A. Mishra, A. Karmakar, A. Ghatak, S. Ghosh, A. Ojha, K. Patra."Low Cost Parking System for Smart Cities: A Vehicle Occupancy Sensing and Resource Optimization Technique Using IoT And Cloud PaaS". International Journal of Scientific \& Technology Research. v.8, Issue 09, September 2019.(journal style)

[25] P. Mell, Grance, T. et al. "The definition of cloud computing”. Computer Security Division, Information Technology Laboratory, National Institute of Standards and Technology Gaithersburg, 2011. Quoted 3 times on pages 19, 23 and 25.(technical report style) 


\section{International Journal of Science and Research (IJSR) \\ ISSN: 2319-7064}

ResearchGate Impact Factor (2018): 0.28 | SJIF (2019): 7.583

[26] A S. T. Nishadi. "Big Data on Cloud Computing, Challenges and Opportunities - A Conceptual Model". International Journal of Science and Research (IJSR) ISSN: 2319-7064 Index Copernicus Value (2016): 79.57 | Impact Factor (2017): 7.296. (journal style)

[27] VH. Pilatti. 2018 "Corruption and Violation of the Principle of Free Competition: Preventive Measures in the Business Sector that can Reduce Such Offenses". Revista Juridica - Fadep / Digital. Accessed: 04/05/2020.(General Internet site)

[28] http://revistajuridica.fadep.br/index.php/revistajuridica/ article/view/103/72. (General Internet site)

[29] B. B. Rao, A. A. Waoo, "Analysis of the Technique for Disaster Recovery in Cloud Computing Environment". International Journal of Science and Research (IJSR) ISSN: 2319-7064 ResearchGate Impact Factor (2018): 0.28 | SJIF (2018): 7.426. (journal style)

[30] S. Warren, L. Brandeis. "The right to privacy". 4 Harvard Law Review, 193, 1890. p. 193-220. Available at: <http: //www.english.illinois.edu/people/faculty/debaron/582/ $582 \%$ 20readings / right $\% 20$ to $\%$ 20privacy.pdf $>$ Accessed: 06/30/2019.(journal style)

[31] DM. West,JR.Allen, "How artificial intelligence is transforming the world. Available at": <https://www.brookings.edu/research/how-artificialintelligence-is-transforming-the-world $/>$. Accessed: 06/30/2019.(journal style)

[32] F. S. dos Reis, RL, Ruaro."The Data Anonymity as a Way to Relax of the Protection of Secondary Information and the Audit of the Court of Audit". REPATS, Brasília, V. 5, $\mathrm{n}^{\circ}$ 2, pp. 157-187, July, 2018.(journal style)

[33] JS. Rossi."Elements of Trade Secrets Management for Innovation". Revista Thesis Juris - RTJ, and ISSN 2317-3580, São Paulo, Vol. 7, n. 1, pp. 25-50, Jan. / Jun, 2018.(journal style)

[34] I.Sarlet, L. G. Marinoni.D. Mitidiero. "Constitutional law course". 5th ed. São Paulo: Saraiva, 2016.(book style)

[35] J.Scheuner, P.Leitner."Performance Benchmarking of Infrastructure-as-a-Service (IaaS) Clouds with Cloud Work Bench”. ICPE '19 Companion, April 7-11, 2019, Mumbai, India, 2019.(journal style)

[36] G. Somasundaram, A. Shrivastava."EMC EDUCATION SERVICES. Information storage and management: How to store, manage and protect digital information". Porto Alegre: Artmed Editora SA, 2011.(book style)

[37] SaS. THE POWER THE KNOW. Available at: https://www.sas.com/pt_br/insights/big-data/what-isbig-data.html. Accessed: 06/30/2019. (journal style)

[38] D.Silva, "What is Cloud Computing". Available at: https://www.estudopratico.com.br/o-que-ecomputacao-em-nuvem/. 06/30/2019.(General Internet site)

[39] G. Tomizawa."The invasion of Privacy Through the Internet”. Curitiba: JM Legal Bookstore, 2008.(book style)

[40] M.Veras."Cloud Computing: new IT architecture". [S1]: Brasport. Quoted 4 times on pages 9, 23, 24 and 28, 2015.(journal style)
[41] SC.Vergara."Projects and research reports in administration”. 15. ed. São Paulo: Atlas, 2014.(book style)

[42] "Collected and edited by Andy Bytheway" Cape Technikon, Cape Town, South Africa

https://www.qinetwork.com.br/infraestrutura-de-ti-emnuvem/Business information management: improving performance using information systems /(General Internet site)

[43] C.Dave, W.Steve. "Prentice Hall Financial Times "dados (data)", in Priberam Dictionary of the Portuguese Language [online], 2008-2013, https://dicionario.priberam.org/dado [access 04/06/2019]. (General Internet site)

[44] http://www.abranet.org.br/Noticias/De-janeiro-a-abril,Brasil-ativou-907-mil-acessos-novos-de-fibra-optica2404.html?UserActiveTemplate=site\#. XPZ7A4hKjIU Accessed: 06/04/2019. (General Internet site)

[45] https://pplware.sapo.pt/internet/a-historia-doarmazenamento-digital/acessado 10/01/ 2020.(General Internet site)

[46] https://www.infonova.com.br/seguranca/tudocompliance-de-ti-importancia-empresas/ Accessed: 06/04/2020.(General Internet site)

\section{Author Profile}

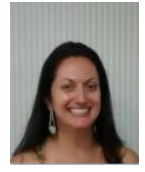

Adriana Maria Miguel Peixe: Doctor student Information Management at the Federal University of Paraná (UFPR). Master in Accounting (2016) from the Federal University of Paraná (UFPR). He holds a degree in Business Administration (2010) Faculdades Borges de Mendonça (BM). Superior Course of Complementation of Studies in the Field of Knowledge in Business Finance (2006) by the University of Southern Santa Catarina (UNISUL). Provider of services in the area of Distance Education (EAD) as tutor and guide of undergraduate and postgraduate courses. I have experience in the following areas: Administrative; Finance and Accounting, working on the following topics: information technology and communication; strategic planning and control; costs; public accounting and fiscal responsibility; financial accounting and finance.

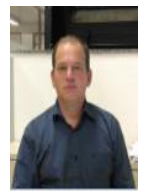

Jorge Balsan: Graduated in Systems Analysis, he has a Specialization in Teleinformatics and Computer Networks and a Masters in Production Engineering from the Federal University of Santa Catarina. He has experience in the area of Technology, Administration and Educational Management.

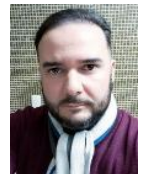

Marcio Rodrigo dos Santos: He holds a Master's Degree in Computer Science from the State University of Londrina UEL (2011), completed a postgraduate degree in Specialization in Teaching Professional, Technical and Technological Education at Medium Level by the Federal Institute of Paraná in 2015, completed a postgraduate degree in Analysis, Project and Systems Management with an Emphasis on Business Intelligence in 2009, I graduated in Data Processing Technology from the Filadelfia University of Londrina - UNIFIL (1999). He is a consultant in business intelligence (BI) and Java developer for Android, C / C ++, .NET and Java, Python and IoT. Has experience in the area of Computer Science, with emphasis on Information Systems and Bioinformatics. He served as Director of Education, Research and Extension, President of the Research and Extension Committee, Coordinator of the Permanent Subcommittee of Teaching Staff. He 


\section{International Journal of Science and Research (IJSR) \\ ISSN: 2319-7064}

ResearchGate Impact Factor (2018): 0.28 | SJIF (2019): 7.583

is coordinator of the Technological Innovation Nucleus and professor of EBTT level D3-4 effective programming at the Federal Institute of Paraná - Campus Colombo.

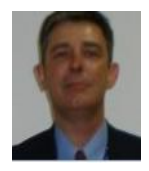

José Simão de Paula Pinto: Graduated in systems analysis, administration and electrical engineering, with specialization in networks and distributed systems; master in computer science, doctor of medicine, with focus on computer science applied to teaching and research in surgery. Worked as a technician in electronics, programmer, systems analyst and support, dba, maintenance manager and teleprocessing. He has experience in IT management and process modeling projects. Associate Teacher at UFPR, he held the position of director of the Electronic Computing Center and coordinated the Master in Science, Management and Information Technology. He coordinates the research group on technologies and methodologies for the management of information and knowledge. Evaluator of INEP, developer at BNIENADE and certifier at ENEM. Interests: Internet of Things, electronics and its technologies, project management, information systems and data analysis. He teaches and researches topics related to information technologies, projects and technologies as a vector of strategic management.

Volume 9 Issue 7, July 2020 www.ijsr.net 